\title{
Effectiveness of Laser Application for Periodontal Surgical Therapy: Systematic Review and Meta-Analysis
}

\author{
Shabnam Behdin, * Alberto Monje, * Guo-Hao Lin, * Bruce Edwards, * Abdullah Othman, * \\ and Hom-Lay Wang*
}

Background: Evidence has shown some improved clinical outcomes and morbidity reduction with the use of lasers for non-surgical periodontal therapy due to ablation, vaporization, hemostasis, and field sterilization. The purpose of this systematic review is to evaluate and compare studies involving lasers as monotherapy or adjunctive to surgical periodontal treatment.

Methods: Electronic and manual searches were conducted by two independent reviewers in several databases for articles written in English up to December 2014. Articles were included in this review if they reported outcomes of surgical periodontal therapy with and without the use of lasers. The primary outcome was probing depth (PD), and secondary outcomes were measured changes in clinical factors such as clinical attachment level (CAL) and gingival recession (GR). For the comparative studies included, the pooled weighted mean difference (WMD) and 95\% confidence interval (CI) of each variable were calculated using random-effects meta-analysis.

Results: Eight and nine articles were included in the quantitative and qualitative analyses, respectively. Although low-to-moderate risk of bias was detected, high heterogeneity among studies was found. In flap surgery with or without laser treatment, there was no statistically significant difference in primary outcome. Similarly, in guided tissue regeneration (GTR)/enamel matrix derivative (EMD) with and without laser treatment, the WMD of PD was negligible; however, the GTR/EMD group showed better outcomes $(P=0.005)$ than the laser group. Regarding the secondary outcomes, in the flap surgery group, the WMD of CAL gain was $1.34 \mathrm{~mm}$, and the WMD of GR was $-0.24 \mathrm{~mm}$; no significant difference was detected between groups. In GTR/EMD with and without laser treatment, the WMD of CAL gain was $0.10 \mathrm{~mm}$ and the WMD of recession was $-0.18 \mathrm{~mm}$; again, no significant difference was detected between groups.

Conclusions: The available evidence is insufficient to support the effectiveness of dental lasers as an adjunct to resective or regenerative surgical periodontal therapy. However, precautions must be exercised when interpreting the results of this study because of the small sample size and high heterogeneity among studies. J Periodontol 2015;86:1352-1363.

\section{KEY WORDS}

Evidence-based dentistry; lasers; meta-analysis; periodontal diseases; periodontitis; review.

\footnotetext{
* Periodontics and Oral Medicine, School of Dentistry, University of Michigan, Ann Arbor, MI.
} 
$\mathrm{P}$ eriodontal disease, an inflammatory disease caused by opportunistic bacteria residing in the oral cavity, causes periodontal breakdown. ${ }^{1}$ Nowadays, periodontal therapy involves not only arresting the disease process, but also regenerating the tissues lost during the disease process. ${ }^{1-5}$ Intervention should be addressed with available treatment modalities. Non-surgical therapy (i.e., scaling and root planing $[S R P])^{6}$ remains an essential part of periodontal therapy. In SRP, diseased root surface debridement with different hand and ultrasonic instrumentation is performed to facilitate periodontal reattachment. Additionally, other non-surgical and surgical techniques such as subgingival curettage, gingivectomy, modified Widman flap, and apically positioned flap have been studied in an attempt to reduce probing depth (PD) and increase clinical attachment level (CAL). ${ }^{7-12}$ Other treatment options aiming to regenerate tissues include guided tissue regeneration (GTR) or the application of growth factors, which have demonstrated varying degrees of success and predictability. ${ }^{1-5}$ Regardless of the treatment modality, surgical periodontal therapy is often associated with pain and discomfort.

In the last decade, the use of lasers (light amplification by stimulated emission of radiation) has occupied part of the dialogue within periodontology and oral surgery because of several proposed advantages. ${ }^{6,13,14}$ In the arena of periodontology, laser use as an adjunct to non-surgical therapy was demonstrated to enhance periodontal healing; ${ }^{15}$ however, it is still a matter of debate. ${ }^{16}$ Advantages over conventional periodontal flap surgeries include ablation, vaporization, hemostasis, pocket sterilization, and morbidity reduction. ${ }^{17,18}$ Lasers are also advantageous in many aspects for periodontal treatment such as effective root surface debridement. ${ }^{17,18}$ Lasers used in this arena include 1) $\mathrm{CO}_{2} ; 2$ ) neodymium:yttrium-aluminum-garnet (Nd: YAG); 3) erbium:yttrium-aluminum-garnet (Er:YAG); and 4) diode lasers. The Er:YAG laser (ERL) has been reported to be the most promising for periodontal treatment. Its ability to ablate dental calculus effectively without overheating adjacent tissue has been demonstrated. ${ }^{17-20}$ Some studies have even pointed out significant CAL gain in conjunction with non-surgical periodontal treatment. ${ }^{19-21}$ Laser systems such as $\mathrm{CO}_{2}$, diode, and Nd:YAG have been used for oral soft tissue procedures (gingivectomy or frenectomy). ${ }^{22,23} \mathrm{CO}_{2}$ lasers have been successfully used as an adjunctive tool to de-epithelialize the mucoperiosteal flap during traditional flap surgery. ${ }^{24}$ Laser treatment, alone or in combination with mechanical treatment (SRP), has produced positive clinical outcomes with respect to CAL gain, decreased PD, and decreased bleeding on probing (BOP). 20,25,26 Similar findings were shown using ERL in the medium term for single-rooted teeth with chronic periodontitis (CP), and outcomes achieved could be maintained over a 5-year period. ${ }^{27}$ The pulsed Nd:YAG laser has been incorporated into protocols that attempt to regenerate lost alveolar bone, cementum, periodontal ligament (PDL), and connective tissue attachment around natural teeth. ${ }^{28-30} \mathrm{~A}$ similar protocol is also used on compromised implant sites in an attempt to regenerate supporting bone. 31,32

Although some evidence ${ }^{15}$ has shown the benefits of using lasers for non-surgical periodontal therapy with regard to clinical outcomes, its effectiveness for surgical therapy remains unclear. Hence, the purpose of this systematic review is to evaluate and compare various lasers as monotherapy or adjunctive to surgical periodontal therapy.

\section{MATERIALS AND METHODS}

\section{Focused Question and Process}

The focused question for this review is, what is the effectiveness of laser adjunctive therapy in periodontal surgical treatment as measured by clinical parameters?

The patient, intervention, comparative, outcome (PICO) ${ }^{33}$ process factors are as follows: P: dentate patients with periodontal disease (chronic or aggressive, moderate or severe), with or without bleeding, with or without exudate, with or without furcation involvement, and with or without gingival recession (GR); I: surgical periodontal treatment using a laser $\left(\mathrm{CO}_{2}\right.$, Nd:YAG, Er:YAG, or diode) approved by the Food and Drug Administration for use in surgical (resective or regenerative) or non-surgical periodontal treatment with or without manual debridement; C: surgical resective or regenerative treatment using approaches other than laser, alone or with laser therapy; and O: benefits or lack thereof in PD reduction, $C A L$ gain, radiographic bone $(\mathrm{RB})$ gain, and decrease in GR, BOP, and exudate.

\section{Eligibility Criteria}

Articles were included in this systematic review if they met the following inclusion criteria: prospective or retrospective, randomized or not, cohort or case series involving human patients in which outcomes of surgical periodontal therapy using lasers were compared with other surgical approaches. Several factors such as study design, number of patients included at the last follow-up assessment, number of defect sites, smoking or other systemic conditions that might alter the outcome, and type of procedure (including whether bone grafting material or barrier membrane was used) were extracted from the selected studies and analyzed. To address the aim of this study comprehensively, parameters such as $\mathrm{PD}, \mathrm{CAL}, \mathrm{BOP}, \mathrm{RB}$ change, suppuration, and GR were further reported (Table 1).21,24,25,33-39 These were subgrouped by initial and final values and change in percent or millimeters, depending on the parameter 


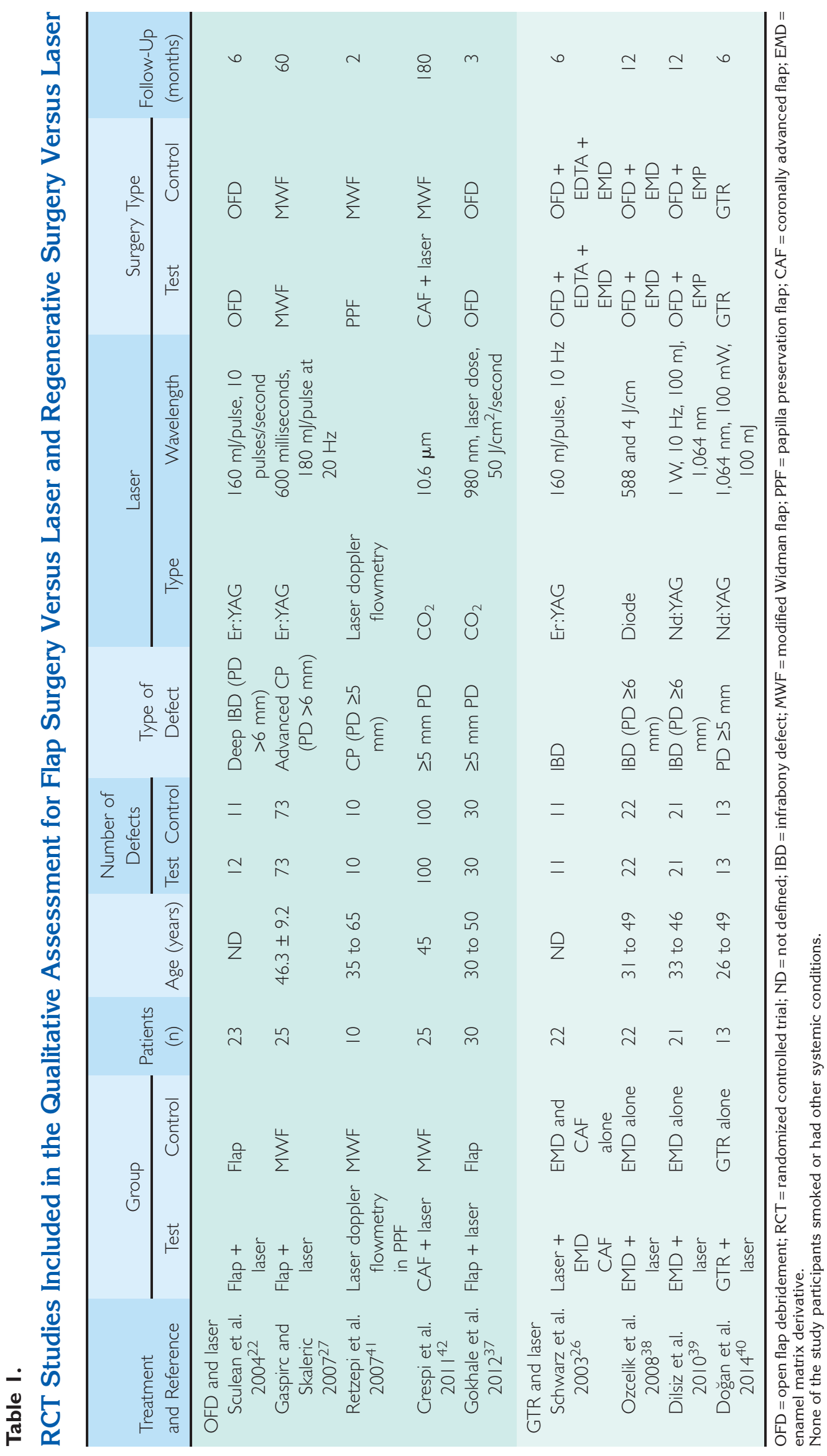




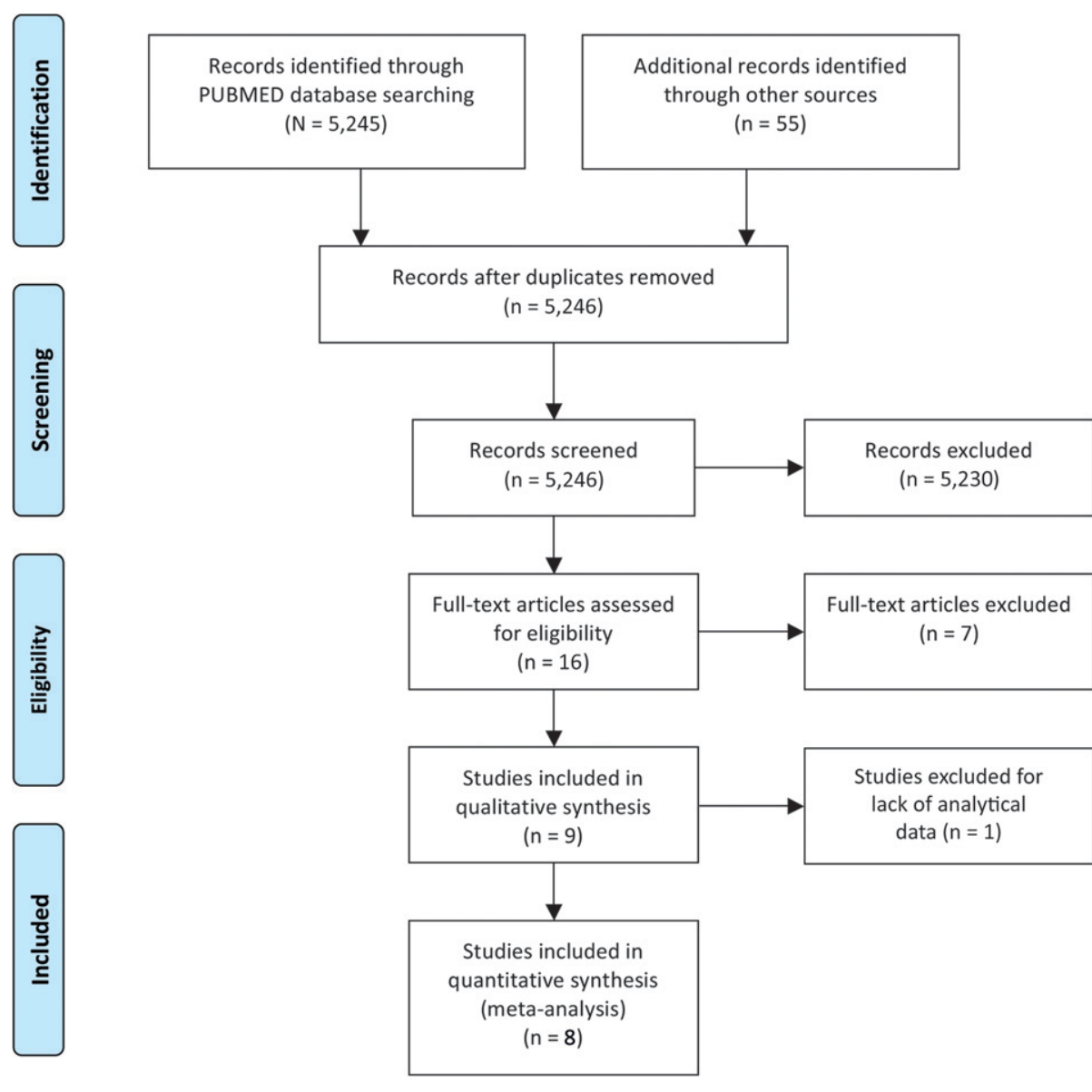

Figure I.

PRISMA flowchart for the screening process.

being studied. Excluded from the review were: 1) case reports or case series with $<10$ patients; 2) systematic reviews; 3 ) preclinical animal studies; 4) human trials studying the use of laser for non-surgical (i.e., SRP) therapy; and 5) human trials with missing information.

\section{Screening Process}

Electronic and manual searches were conducted by two independent reviewers (SB and $\mathrm{AM}$ ) in four databases (MEDLINE, EMBASE, Cochrane Central Register of Controlled Trials, and Cochrane Oral Health Group Trials Register databases) for articles written in English up to December 2014. For the PubMed library, combinations of controlled terms (MeSH and EMTREE) and key words were used whenever possible. The search terms used in title and abstract were as follows: (bone loss, periodontal[MeSH Terms] OR debridement, periodontal[MeSH Terms] OR debridement, periodontal epithelial[MeSH Terms] OR periodontal atrophy[MeSH Terms]) OR adult periodontitis[MeSH Terms] AND (periodontal[Other Term] OR periodontal flap[Other Term]) AND (carbon dioxide lasers[MeSH Terms] OR erbium YAG laser[MeSH Terms] OR ablation, laser tissue $[\mathrm{MeSH}$ Terms] OR Doppler laser flowmetry[MeSH Terms] OR diode laser[MeSH Terms] OR lasers, neodymium doped yttrium aluminum garnet[MeSH Terms]) AND English language[filter] AND clinical trial[filter] AND humans[filter]. For the Embase and Cochrane Libraries, the terms were restricted to the aim of the study. The key terms applied for the Embase Library were as follows: laser AND periodontal AND surgery OR periodontal AND disease OR periodontal AND treatment AND clinical trials AND humans. For the Cochrane Library, laser periodontal surgery was applied in Title, Abstract, and Keywords in Trials. Additionally, to ensure a thorough screening process, a manual search was performed of periodontics-related journals, including Journal of Dental Research, Journal of Clinical Periodontology, Journal of Periodontology, and The International Journal of Periodontics \& Restorative Dentistry from January 2014 to December 2014. References of included articles were screened to check all available articles.

Two reviewers (AM and G-HL) designed and assessed the proposal for the project to make sure the Preferred Reporting Items for Systematic Reviews and Meta-Analyses (PRISMA) guideline was followed to minimize risk of bias in the screening process and provide a high level of evidence. PRISMA consists of a 27 -item checklist and a four-phase flow diagram. ${ }^{34}$

\section{Qualitative Assessment}

Criteria used to evaluate the quality of the selected randomized controlled trials (RCTs) were modified from the randomized clinical trial checklist of the Cochrane Center and the Consolidated Standards of Reporting Trials (CONSORT) statement, ${ }^{35}$ which provides guidelines for the following parameters: 1) sequence generation; 2) allocation concealment method; 3) masking of the examiner; 4) address of incomplete outcome data; 5) free of selective outcome reporting; and 6) patient accounting at the end of the study. The degree of bias was categorized as low risk if all the criteria were met, moderate risk if one criterion was missing, and high 

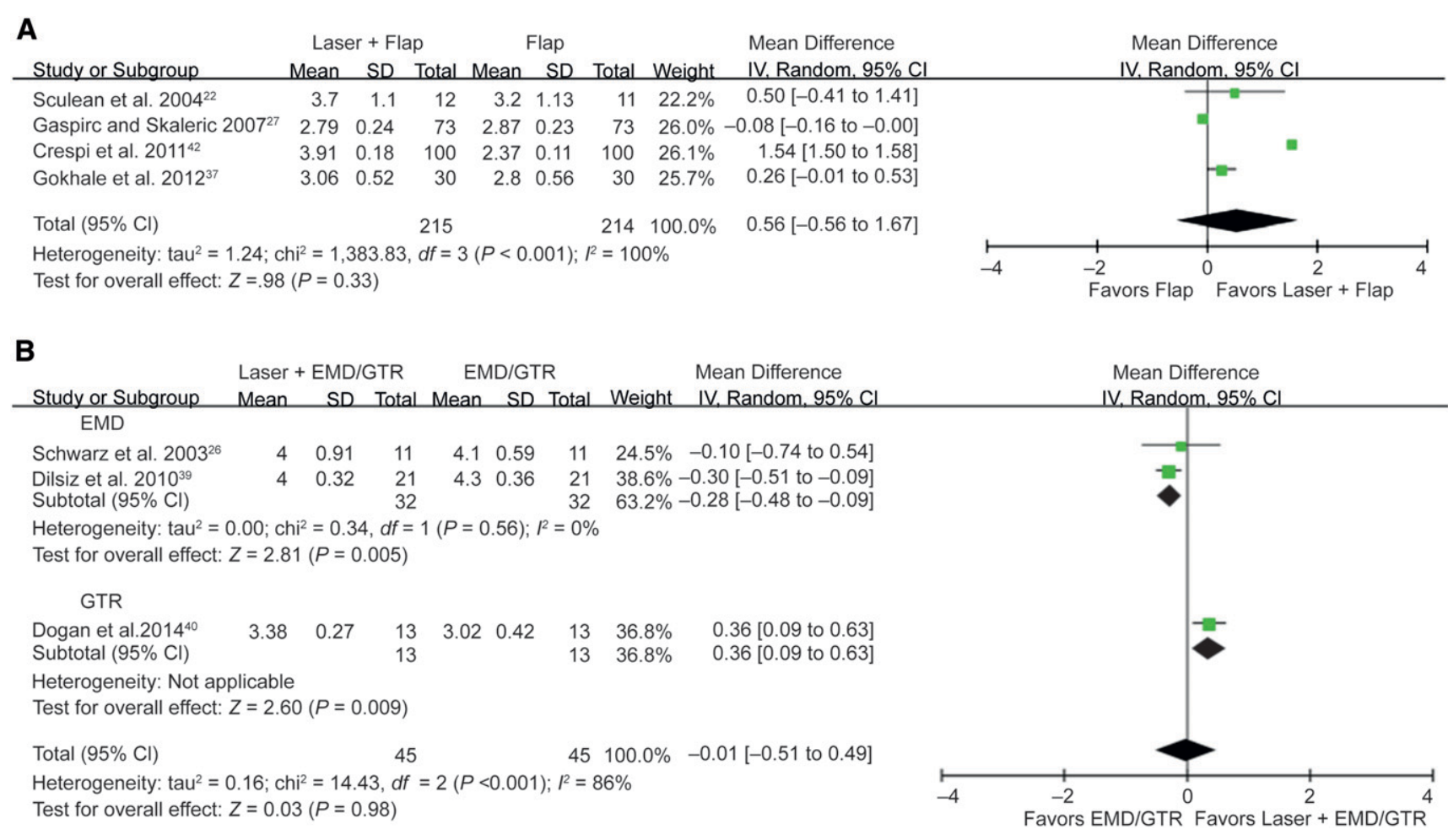

Figure 2.

A) Meta-analysis for comparison of PD among selected studies in flap surgery with and without laser treatment. The overall WMD was $0.56 \mathrm{~mm}(95 \%$ $\mathrm{Cl}=-0.56$ to $1.67 \mathrm{~mm}, \mathrm{P}=0.33)$. B) Meta-analysis for comparison of PD among selected studies in GTR/EMD with and without laser treatment. The overall WMD was $-0.01 \mathrm{~mm}(95 \% \mathrm{Cl}=-0.51$ to $0.49 \mathrm{~mm}, \mathrm{P}=0.98) . \mathrm{IV}=$ independent variable.

risk if $\geq 2$ criteria were missing. ${ }^{36}$ Two independent reviewers ( $\mathrm{SB}$ and $\mathrm{AM}$ ) evaluated all the included articles.

\section{Statistical Analyses}

The primary outcome was PD reduction, and the secondary outcomes were CAL gain and GR reduction. BOP, suppuration, and RB change could not be metaanalyzed because of the high heterogeneity in studies reporting them.

Because of the variance in study designs and laser types, the analysis was divided into two subgroups: 1) flap surgery with and without laser treatment; and 2) GTR/enamel matrix derivative (EMD) with and without laser treatment. For the comparative studies included, the pooled weighted mean difference (WMD) and 95\% confidence interval (CI) of each variable were calculated with random-effects metaanalysis by a computer program. ${ }^{\dagger}$ Forest plots were produced to graphically represent WMD and 95\% CI in primary and secondary outcomes for the studies, using number of defect sites investigated as the analysis unit. In addition, heterogeneity among studies was assessed with the $\chi^{2}$ test, with a $P$ value $<0.05$ representing significant heterogeneity. Funnel plots were also generated to report potential publication bias.

\section{RESULTS}

\section{Study Selection}

An initial screening yielded a total of 5,446 articles, of which 16 potentially relevant ${ }^{13,20,22,26-28,37-46}$ articles were selected after an evaluation of titles and abstracts. The full texts of these articles were obtained and thoroughly evaluated. Nine articles $22,26,27,37-42$ fulfilled the inclusion criteria and are included in the systematic review. Because of the lack of analytical data, one of these studies was excluded; ${ }^{41}$ thus, only eight articles $^{22,26,27,37-40,42}$ are included in the quantitative analysis (Fig. 1). Details of all included studies were summarized in Table 1 . Briefly, for open-flap debridement (OFD), 103 individuals were included, and for GTR/OFD + EMD, 78 individuals were included. Reasons for exclusion are displayed in supplementary Table 1 in online Journal of Periodontology.

\section{Study Quality}

All the studies included in the qualitative and quantitative analyses were RCTs. The RCT checklist of the Cochrane Center and the CONSORT statement were used to score studies' quality (see supplementary Table 2 in online Journal of Periodontology). Low

\footnotetext{
$\dagger$ Review Manager, v.5.0, The Nordic Cochrane Centre, Copenhagen Denmark.
} 


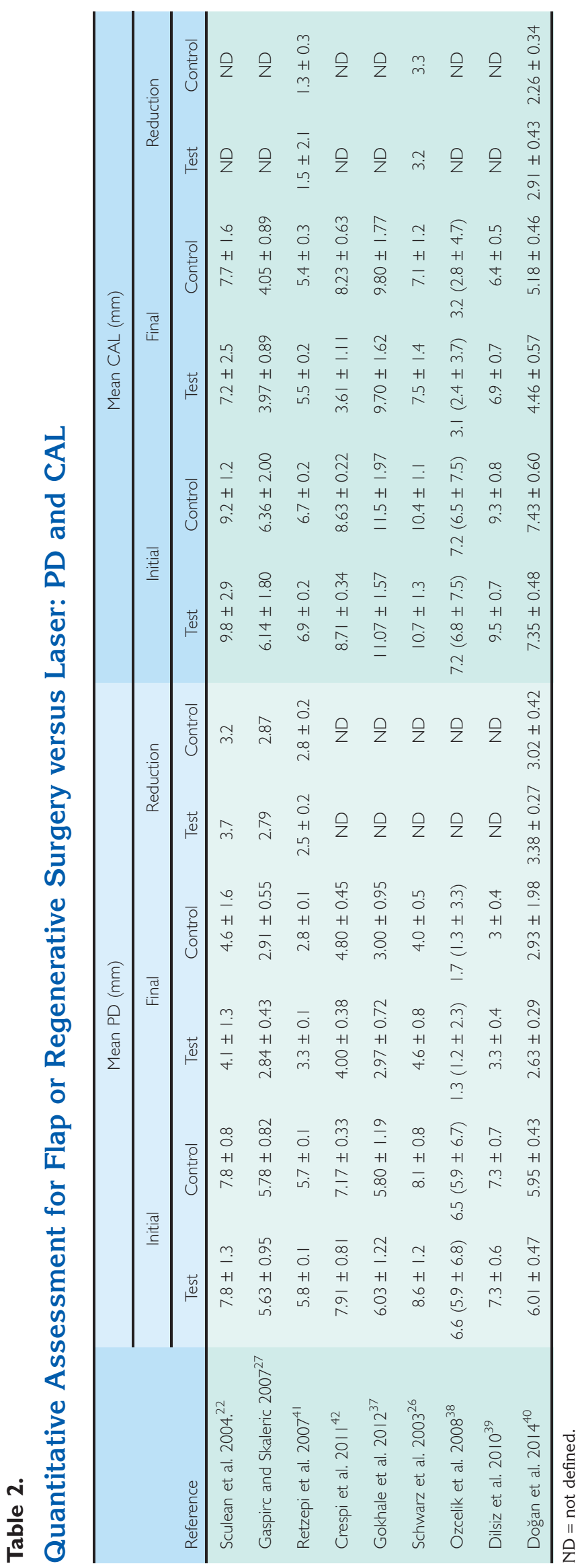

(55.5\% of studies) to moderate ( $44.5 \%$ of studies) estimated potential risk of bias was found from the studies included in the qualitative appraisal.

\section{Results of the Primary Outcome (PD)}

In flap surgery with and without laser treatment, the WMD of PD was $0.56 \mathrm{~mm}(95 \% \mathrm{Cl}=-0.56$ to $1.67 \mathrm{~mm}$, $P=0.33$ ) (Fig. 2A). No significant difference was detected among groups. A high degree of heterogeneity $\left(P<0.001\right.$ for $X^{2}$ test) was noted.

In GTR/EMD with and without laser treatment, the WMD of PD was $-0.01 \mathrm{~mm}(95 \% \mathrm{Cl}=-0.51$ to 0.49 $\mathrm{mm}, P=0.98$ ) (Fig. 2B). No significant difference was detected between groups. A high degree of heterogeneity $\left(P<0.001\right.$ for $\chi^{2}$ test) was noted. Interestingly, in the EMD subgroup, the meta-analysis showed a significantly favorable outcome toward the EMD/GTR-only group $(P=0.005)$, with a low degree of heterogeneity between studies ( $P=0.56$ for $\chi^{2}$ test).

Data for the initial, final, and reduction in mean PD for the included studies are presented in Table 2.

\section{Results of the Secondary Outcome (CAL gain and GR decrease)}

In flap surgery with and without laser treatment, the WMD of CAL gain was $1.34 \mathrm{~mm}(95 \% \mathrm{CI}=-2.02$ to $4.70 \mathrm{~mm}, P=0.44$ ) (Fig. 3A). No significant difference was detected among groups. The $P$ value for $X^{2}$ test was $<0.001$, indicating a high heterogeneity among studies. In GTR/EMD with and without laser treatment, the WMD of CAL gain was $0.10 \mathrm{~mm}(95 \% \mathrm{Cl}=-0.64$ to $0.85 \mathrm{~mm}, P=0.78$ ) (Fig. $3 \mathrm{~B}$ ). No significant difference was detected among groups. The $P$ value for $\chi^{2}$ test was $<0.001$, indicating a high heterogeneity among studies. However, in the EMD subgroup, the meta-analysis showed a significantly favorable outcome toward EMD/GTR without the use of laser $(P=$ 0.03 ), with a low degree of heterogeneity among studies ( $P$ value for $X^{2}$ test 0.69 ). Data for the initial, final, and reduction in mean CAL for the included studies are presented in Table 2.

The WMD of GR was $-0.24 \mathrm{~mm}(95 \% \mathrm{CI}=-0.82$ to $0.35 \mathrm{~mm}, P=0.42$ ) (Fig. $4 \mathrm{~A}$ ). No significant difference was detected among groups. The $P$ value for $\chi^{2}$ test was 0.18 , indicating a moderate degree of heterogeneity among studies. Additionally, the WMD of GR was $-0.18 \mathrm{~mm}(95 \% \mathrm{Cl}$ -0.42 to $0.07 \mathrm{~mm}, P=0.15$ ) in the comparison of EMD/GTR with and without the use of lasers (Fig. 4B). No significant difference was detected. The $P$ value for $\chi^{2}$ test was 0.59 , indicating a low degree of heterogeneity among studies. Data for initial, final, and reduction in mean BOP, mean GR, and discomfort are presented in Table 3.

Funnel plots evaluating the publication bias of each parameter are shown in supplementary Figures 1 through 6 in online Journal of Periodontology. 

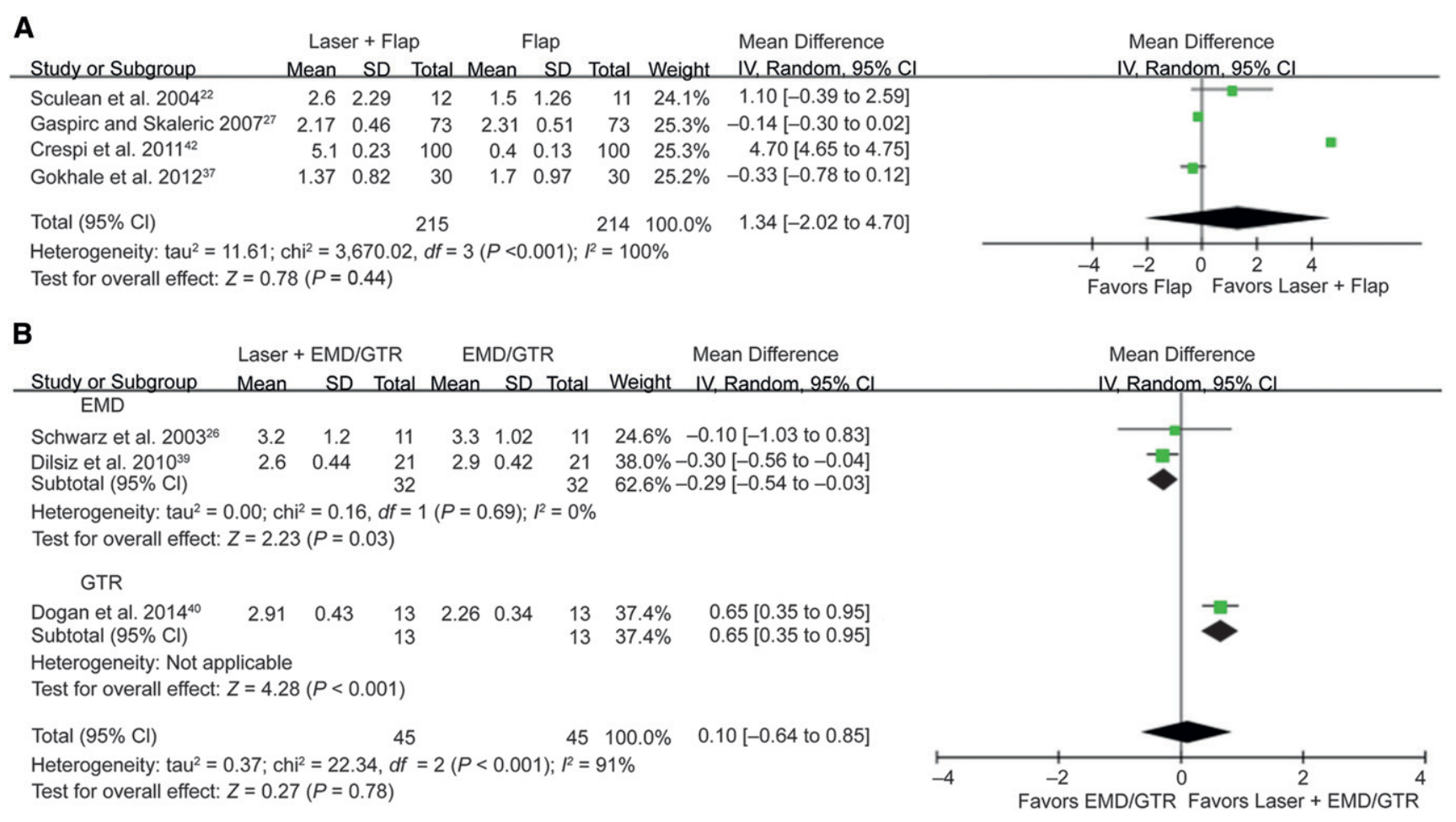

Figure 3.

A) Meta-analysis for comparison of CAL gain among selected studies in flap surgery with and without laser treatment. The overall WMD was $1.34 \mathrm{~mm}$ (95\% Cl=-2.02 to $4.70 \mathrm{~mm}, \mathrm{P}=0.44$ ). B) Meta-analysis for comparison of CAL gain among selected studies in GTR/EMD with and without laser treatment. The overall WMD was $0.10 \mathrm{~mm}(95 \% \mathrm{Cl}-0.64$ to $0.85 \mathrm{~mm}, \mathrm{P}=0.78) . \mathrm{IV}=$ independent variable.

\section{DISCUSSION}

The effective applicability of lasers in the treatment of periodontal disease according to their theoretic advantages (i.e., ablation or vaporization, hemostasis, and sterilization effect) compared to conventional therapy is currently a very controversial topic in clinical periodontics. Findings from this study show that for regeneration and PD reduction surgical procedures, adjunctive use of lasers offers no significant clinical advantages in CAL gain and PD reduction compared with conventional approaches. These results must be cautiously interpreted, since limitations exist in regard to sample size and heterogeneity among studies.

\section{Summary of Main Findings}

Different types of laser, including $\mathrm{CO}_{2}$, Nd:YAG, Er: YAG, and diode, have been used for periodontal disease treatment and hard and soft tissue management. ${ }^{15,16,47}$ Laser irradiation, at low level, stimulates surrounding tissue cells and results in reduction of inflammation, higher tissue regeneration, better tissue attachment, and even increased lymph flow, as well as less postoperative pain, once the scattered beams penetrate into pockets. ${ }^{48}$ Smooth and flat root surfaces with sealed dentinal tubules as well as bacterial elimination can be obtained using $\mathrm{CO}_{2}$ lasers (in defocused pulsed mode with power of $2 \mathrm{~W}$ ), which in turn enhance fibroblast attachment. ${ }^{49}$ A diode laser with wavelength of 810 or 910 to $980 \mathrm{~nm}$ is a useful setup for soft tissue management (coagulating and cutting gingiva or oral mucosa, sulcular debridement) and has antibacterial effects. ${ }^{50}$ It must be noted that $\mathrm{CO}_{2}$, Nd:YAG, and diode lasers are not effective in treating or dealing with hard tissue surfaces in terms of calculus removal. ${ }^{23,49}$ In contrast, the ERL has the ability to effectively ablate dental calculus without creating thermal damage to adjacent tissue. ${ }^{19}$ ERL has a wavelength of $2,940 \mathrm{~nm}$, close to the absorption coefficient of water, making it safe and free of thermal side effects. ${ }^{23}$ Moreover, ERL has antimicrobial effects and works to remove lipopolysaccharide from root surfaces. ${ }^{23}$ In the present study, it was not the aim to compare the effectiveness of laser subtypes, and no particular one was found to be superior.

\section{Agreements and Disagreements With Previous Studies}

In contrast to these findings, a long-term follow-up study $^{42}$ showed that in deep pockets (PD $\geq 7 \mathrm{~mm}$ ), a coronally advanced flap combined with $\mathrm{CO}_{2}$ laser provides greater PD reduction compared with a modified Widman flap procedure. A similar trend was also noted in CAL assessment. It was then concluded 
A

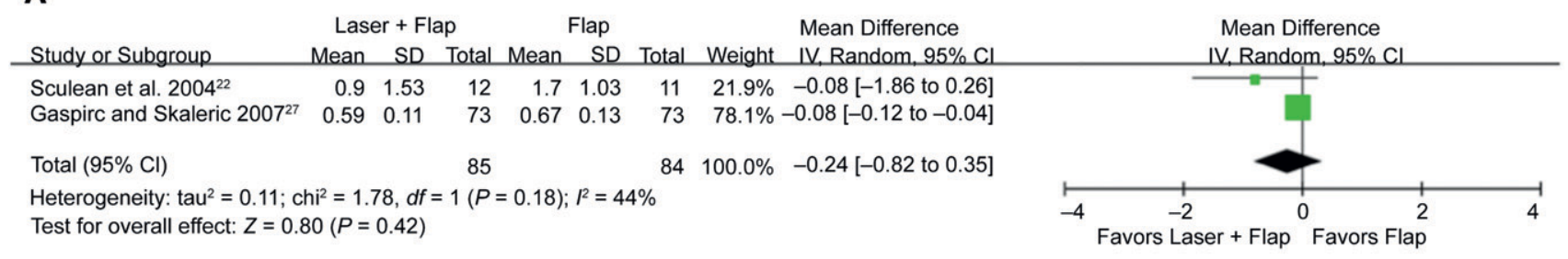

B

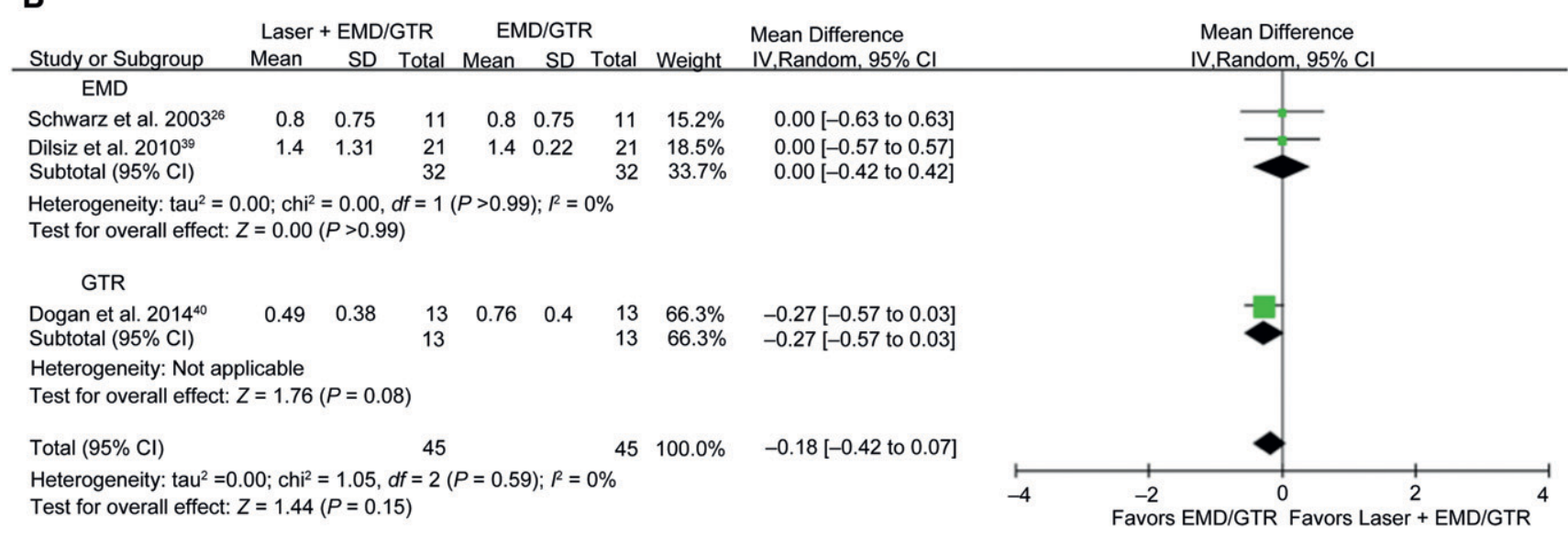

Figure 4.

A) Meta-analysis for comparison of GR among selected studies in flap surgery with and without laser treatment. The overall WMD was $-0.24 \mathrm{~mm}$ ( $95 \% \mathrm{Cl}=-0.82$ to $0.35 \mathrm{~mm}, \mathrm{P}=0.42$ ). B) Meta-analysis for comparison of $G R$ among selected studies in GTR/EMD with and without laser treatment. The overall WMD was $-0.18 \mathrm{~mm}(95 \% \mathrm{Cl}=-0.42$ to $0.07 \mathrm{~mm}, \mathrm{P}=0.15)$. IV = independent variable.

that $\mathrm{CO}_{2}$ lasers might provide meaningful clinical benefits in the treatment of deep pockets. These findings have been partially attributed to the ability of the $\mathrm{CO}_{2}$ laser to remove the smear layer and eliminate bacterial cells from diseased root surfaces. ${ }^{51}$ Also, myofibroblasts, which are suggested to be responsible for tissue contraction, are less abundant after treatment with $\mathrm{CO}_{2}$ lasers, ${ }^{51}$ which may be another rationale for better CAL gain in the test group. Nonetheless, the findings may be attributed not just to the laser, but also to the study design, in which no similar surgical procedures were evaluated. Moreover, this specific study showed no crater formation or root surface damage resulting from laser therapy. These results were in contrast to previously reported studies. ${ }^{51-54}$

Other studies ${ }^{26,37,39}$ are in agreement with the present findings. In a comparative evaluation ${ }^{37}$ of the efficiency of the diode laser as an adjunct to mechanical debridement versus conventional mechanical debridement in periodontal open flap surgery, no difference was found between laser-treated and nonlaser-treated groups with regard to clinical parameters. However, it was reported 37 that the use of laser treatment adjunctive to open flap debridement provides a beneficial effect by reduction of anaerobic bacterial colonies within the sulci. The antiseptic potential of lasers was explained based on laser energy disrupting the protective mechanism of the organisms. ${ }^{55}$ The visual analog scale showed that patients tolerated application of the diode laser; nonetheless, its application did not make a difference in pain perception. 55 Similar findings were reported by another group. ${ }^{37}$

Dental lasers have slight advantages but also some inherent drawbacks that have to be pointed out, including possible damage to bone owing to overheating and ineffectiveness in removing calculus. Hence, intermittent laser application and correct laser settings are key factors to reduce potential damage. Another investigation using ERL for the surgical treatment of chronic periodontal disease ${ }^{26}$ found no statistically significant clinical differences compared with resective procedures.

Dental lasers have been applied and investigated for regenerative procedures (i.e., GTR). ${ }^{38,56}$ In a shortterm study, ${ }^{56}$ patients with $\mathrm{CP}$ who had intrabony defects and were receiving treatment with GTR in combination with low-level laser therapy demonstrated statistically better improvements in PD reduction, CAL gain, and decreased GR at 6 months versus the group who received GTR alone. Additionally, a significant reduction of the sulcular bleeding index favored the laser-treated group. These findings 


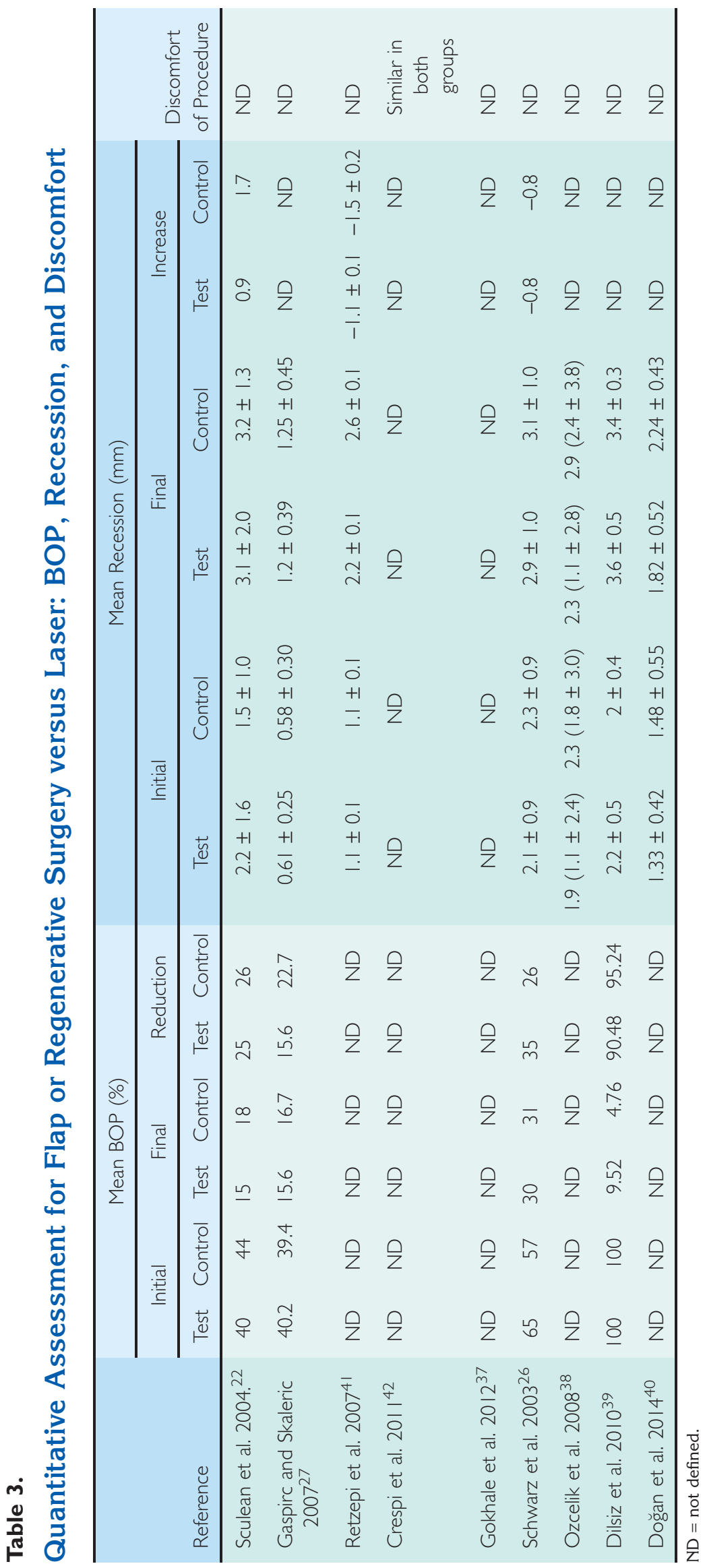

were partially corroborated with the same laser type by other studies carrying out other periodontal regenerative approaches. ${ }^{38,56}$ Thus, it seems that low-level laser therapy as an adjunct to GTR may improve shortterm clinical outcomes. Some in vitro studies were conducted to evaluate the responsiveness of PDL cells to low-level laser therapy. ${ }^{57-59}$ Less collagen breakdown after laser irradiation was described in terms of plasminogen activator plasmin proteolytic system inhibition with the use of lasers. ${ }^{60}$ Additionally, sites treated with an 809-nm laser showed higher fibroblast proliferation as well as increased production of basic fibroblast growth factor. ${ }^{59}$ This can be mainly attributed to the stimulatory effect of laser therapy on PDL cell regeneration. ${ }^{59}$

Contrary to previous findings ${ }^{38,40,42}$ and in agreement with ours, Dilsiz et al. ${ }^{39} \mathrm{com}$ pared the clinical outcomes of enamel matrix proteins (EMP) alone and combined with Nd:YAG laser in the treatment of infrabony defects. They reported that the use of Nd: YAG laser did not have superiority over EDTA as a root conditioning agent. ${ }^{39}$ Along these lines, it is important to mention that consensus is lacking that EMP as a biologic agent enhances clinical outcomes compared to GTR procedures using barrier membranes. ${ }^{61-64}$ Also noteworthy is that there are still controversies in the literature regarding the effectiveness of root conditioning agents. ${ }^{65-67}$ Other studies demonstrated the efficacy of laser application as a root biomodification instrument to achieve better periodontal regenerative outcome by means of new attachment formation. ${ }^{68-70}$ Cementum biocompatibility alteration using Nd:YAG laser for more predictable new attachment after periodontium regeneration has also been demonstrated. ${ }^{70}$

\section{Limitations of the Study}

Finally, it is important to highlight some evident limitations found in the qualitative assessment of articles using dental lasers as an adjunct to regeneration. For instance, defect morphology can potentially affect the final outcome. Steffensen and Webert showed statistically better results for defects angled $<45$ degrees. As a matter of fact, wider defects had higher RB loss. ${ }^{71}$ Likewise, Cortellini and Tonetti demonstrated 
that in scenarios of radiographic angulation $\leq 25$ degrees, presence of a deep infrabony defect ( $\geq 3 \mathrm{~mm}$ ), and $\geq 1 \mathrm{~mm}$ of gingival thickness over the site, the most consistent CAL and bone gains were achieved, regardless of the number of bony walls. ${ }^{72}$ Many factors contribute to the results of any regenerative procedure, and precautions must be exercised when interpreting the present findings.

Moreover, it is essential to understand the limitations of the present review based on the heterogeneity of the studies included. Certainly, all the included studies were RCTs; nonetheless, as evaluated by the CONSORT statement, $44.5 \%$ have moderate risk of bias, mainly on two sections: 1) masking examiner and 2) selective outcome reporting. In such a controversial topic, where conflict of interest might play a major role in the outcome, studies on this matter must be cautiously interpreted to avoid misleading readers.

\section{CONCLUSIONS}

Within the limits of this study, this systematic review fails to support the effectiveness of dental lasers as an adjunct to resective or regenerative surgical periodontal therapy, owing to the lack of significant superiority over conventional approaches. Precautions must be exercised when interpreting the results of this study because of the small sample size and high heterogeneity among studies. Therefore, more randomized clinical trials examining different laser types and wavelengths are required to obtain stronger conclusions in this regard.

\section{ACKNOWLEDGMENTS}

This paper was partially supported by the University of Michigan Periodontal Graduate Student Research Fund. $\mathrm{H}$-LW receives financial support for lecturing from Morita Corp. (Osaka, Japan). The other authors do not have any financial interests, either directly or indirectly, in the products or information listed in the paper.

\section{REFERENCES}

1. Bowers GM, Granet M, Stevens M, et al. Histologic evaluation of new attachment in humans. A preliminary report. J Periodontol 1985;56:381-396.

2. Mellonig JT. Decalcified freeze-dried bone allograft as an implant material in human periodontal defects. Int $J$ Periodontics Restorative Dent 1984;4:40-55.

3. Sanders JJ, Sepe WW, Bowers GM, et al. Clinical evaluation of freeze-dried bone allografts in periodontal osseous defects. Part III. Composite freeze-dried bone allografts with and without autogenous bone grafts. J Periodontol 1983;54:1-8.

4. Quintero G, Mellonig JT, Gambill VM, Pelleu GB Jr. A six-month clinical evaluation of decalcified freeze-dried bone allografts in periodontal osseous defects. J Periodontol 1982;53:726-730.

5. Bowers GM, Schallhorn RG, Mellonig JT. Histologic evaluation of new attachment in human intrabony defects. A literature review. J Periodontol 1982;53: 509-514.

6. Yukna RA. Lasers in periodontal therapy. Todays FDA 2011;23:40-41.

7. Ramfjord SP, Nissle RR. The modified Widman flap. J Periodontol 1974;45:601-607.

8. Ramfjord SP. Present status of the modified Widman flap procedure. J Periodontol 1977;48:558-565.

9. Ramfjord SP, Caffesse RG, Morrison EC, et al. 4 modalities of periodontal treatment compared over 5 years. J Clin Periodontol 1987;14:445-452.

10. Carnevale G, Kaldahl WB. Osseous resective surgery. Periodontol 2000 2000;22:59-87.

11. Becker W, Becker BE, Caffesse R, et al. A longitudinal study comparing scaling, osseous surgery, and modified Widman procedures: Results after 5 years. J Periodontol 2001;72:1675-1684.

12. Kaldahl WB, Kalkwarf KL, Patil KD, Dyer JK, Bates RE Jr. Evaluation of four modalities of periodontal therapy. Mean probing depth, probing attachment level and recession changes. J Periodontol 1988;59:783-793.

13. Nevins ML, Camelo M, Schupbach P, Kim SW, Kim DM, Nevins M. Human clinical and histologic evaluation of laser-assisted new attachment procedure. Int $J$ Periodontics Restorative Dent 2012;32:497-507.

14. Nevins M, Nevins ML, Yamamoto A, et al. Use of Er: YAG laser to decontaminate infected dental implant surface in preparation for reestablishment of bone-toimplant contact. Int $J$ Periodontics Restorative Dent 2014;34:461-466.

15. Schwarz F, Aoki A, Becker J, Sculean A. Laser application in non-surgical periodontal therapy: A systematic review. J Clin Periodontol 2008;35(Suppl. 8):29-44.

16. Sgolastra F, Petrucci A, Gatto R, Monaco A. Efficacy of Er:YAG laser in the treatment of chronic periodontitis: Systematic review and meta-analysis. Lasers Med Sci 2012;27:661-673.

17. Aoki A, Ando Y, Watanabe H, Ishikawa I. In vitro studies on laser scaling of subgingival calculus with an erbium: YAG laser. J Periodontol 1994;65:1097-1106.

18. Israel M, Cobb CM, Rossmann JA, Spencer P. The effects of $\mathrm{CO}_{2}$, Nd:YAG and Er:YAG lasers with and without surface coolant on tooth root surfaces. An in vitro study. J Clin Periodontol 1997;24:595-602.

19. Schwarz F, Pütz N, Georg T, Reich E. Effect of an Er: YAG laser on periodontally involved root surfaces: An in vivo and in vitro SEM comparison. Lasers Surg Med 2001;29:328-335.

20. Schwarz F, Sculean A, Georg T, Reich E. Periodontal treatment with an Er:YAG laser compared to scaling and root planing. A controlled clinical study. J Periodontol 2001;72:361-367.

21. Watanabe H, Ishikawa I, Suzuki M, Hasegawa K. Clinical assessments of the erbium:YAG laser for soft tissue surgery and scaling. J Clin Laser Med Surg 1996; 14:67-75.

22. Sculean A, Schwarz F, Berakdar $M$, Windisch $P$, Arweiler NB, Romanos GE. Healing of intrabony defects following surgical treatment with or without an Er: YAG laser. J Clin Periodontol 2004;31:604-608.

23. Sculean A, Schwarz F, Berakdar M, Romanos GE, Arweiler NB, Becker J. Periodontal treatment with an Er:YAG laser compared to ultrasonic instrumentation: A pilot study. J Periodontol 2004;75:966-973.

24. Centty IG, Blank LW, Levy BA, Romberg E, Barnes DM. Carbon dioxide laser for de-epithelialization of periodontal flaps. J Periodontol 1997;68:763-769. 
25. Tomasi C, Schander K, Dahlén G, Wennström JL. Short-term clinical and microbiologic effects of pocket debridement with an Er:YAG laser during periodontal maintenance. J Periodontol 2006;77:111-118.

26. Schwarz F, Sculean A, Georg T, Becker J. Clinical evaluation of the Er:YAG laser in combination with an enamel matrix protein derivative for the treatment of intrabony periodontal defects: A pilot study. J Clin Periodontol 2003;30:975-981.

27. Gaspirc B, Skaleric U. Clinical evaluation of periodontal surgical treatment with an Er:YAG laser: 5-year results. J Periodontol 2007;78:1864-1871.

28. Yukna RA, Carr RL, Evans GH. Histologic evaluation of an Nd:YAG laser-assisted new attachment procedure in humans. Int J Periodontics Restorative Dent 2007;27: 577-587.

29. Fornaini C, Rocca JP, Bertrand MF, Merigo E, Nammour $S$, Vescovi P. Nd:YAG and diode laser in the surgical management of soft tissues related to orthodontic treatment. Photomed Laser Surg 2007;25:381-392.

30. de Andrade AK, Feist IS, Pannuti CM, Cai S, Zezell DM, De Micheli G. Nd:YAG laser clinical assisted in class II furcation treatment. Lasers Med Sci 2008;23:341-347.

31. Deppe H, Horch HH. Laser applications in oral surgery and implant dentistry. Lasers Med Sci 2007;22:217-221.

32. Giannini R, Vassalli M, Chellini F, Polidori L, Dei R, Giannelli $M$. Neodymium:yttrium aluminum garnet laser irradiation with low pulse energy: A potential tool for the treatment of peri-implant disease. Clin Oral Implants Res 2006;17:638-643.

33. Stone PW. Popping the (PICO) question in research and evidence-based practice. Appl Nurs Res 2002;15:197198.

34. Liberati A, Altman DG, Tetzlaff J, et al. The PRISMA statement for reporting systematic reviews and metaanalyses of studies that evaluate health care interventions: Explanation and elaboration. PLoS Med 2009;6: e1000100.

35. Hopewell S, Clarke M, Moher D, et al; CONSORT Group. CONSORT for reporting randomized controlled trials in journal and conference abstracts: Explanation and elaboration. PLoS Med 2008;5:e20.

36. Schulz KF, Altman DG, Moher D. CONSORT 2010 statement: Updated guidelines for reporting parallel group randomised trials. J Pharmacol Pharmacother 2010;1: 100-107.

37. Gokhale SR, Padhye AM, Byakod G, Jain SA, Padbidri V, Shivaswamy S. A comparative evaluation of the efficacy of diode laser as an adjunct to mechanical debridement versus conventional mechanical debridement in periodontal flap surgery: A clinical and microbiological study. Photomed Laser Surg 2012;30: 598-603.

38. Ozcelik O, Cenk Haytac M, Seydaoglu G. Enamel matrix derivative and low-level laser therapy in the treatment of intra-bony defects: A randomized placebo-controlled clinical trial. J Clin Periodontol 2008;35:147-156.

39. Dilsiz A, Canakci V, Aydin T. The combined use of Nd: YAG laser and enamel matrix proteins in the treatment of periodontal infrabony defects. J Periodontol 2010; 81:1411-1418.

40. Doğan GE, Demir T, Orbak R. Effect of low-level laser on guided tissue regeneration performed with equine bone and membrane in the treatment of intrabony defects: A clinical study. Photomed Laser Surg 2014;32:226-231.

41. Retzepi M, Tonetti M, Donos N. Comparison of gingival blood flow during healing of simplified papilla preser- vation and modified Widman flap surgery: A clinical trial using laser Doppler flowmetry. J Clin Periodontol 2007;34:903-911.

42. Crespi R, Cappare P, Gherlone E, Romanos GE. Comparison of modified Widman and coronally advanced flap surgery combined with $\mathrm{CO}_{2}$ laser root irradiation in periodontal therapy: A 15-year follow-up. Int J Periodontics Restorative Dent 2011;31:641-651.

43. White JM, Goodis HE, Rose CL. Use of the pulsed Nd: YAG laser for intraoral soft tissue surgery. Lasers Surg Med 1991;11:455-461.

44. Rotundo R, Nieri M, Cairo F, et al. Lack of adjunctive benefit of Er:YAG laser in non-surgical periodontal treatment: A randomized split-mouth clinical trial. $J$ Clin Periodontol 2010;37:526-533.

45. Belal $\mathrm{MH}$, Watanabe H. Comparative study on morphologic changes and cell attachment of periodontitisaffected root surfaces following conditioning with $\mathrm{CO}_{2}$ and Er:YAG laser irradiations. Photomed Laser Surg 2014;32:553-560.

46. Miyazaki A, Yamaguchi T, Nishikata J, et al. Effects of Nd:YAG and $\mathrm{CO}_{2}$ laser treatment and ultrasonic scaling on periodontal pockets of chronic periodontitis patients. J Periodontol 2003;74:175-180.

47. Sgolastra F, Petrucci A, Gatto R, Monaco A. Effectiveness of laser in dentinal hypersensitivity treatment: A systematic review. J Endod 2011;37:297-303.

48. Gokhale R, Agarkar S, Debgupta J, et al. Laser synthesized super-hydrophobic conducting carbon with broccolitype morphology as a counter-electrode for dye sensitized solar cells. Nanoscale 2012;4:6730-6734.

49. Crespi R, Barone A, Covani U, Ciaglia RN, Romanos GE. Effects of $\mathrm{CO}_{2}$ laser treatment on fibroblast attachment to root surfaces. A scanning electron microscopy analysis. J Periodontol 2002;73:1308-1312.

50. Sanz-Moliner JD, Nart J, Cohen RE, Ciancio SG. The effect of an 810-nm diode laser on postoperative pain and tissue response after modified Widman flap surgery: A pilot study in humans. $J$ Periodontol 2013;84: 152-158.

51. Tucker D, Cobb CM, Rapley JW, Killoy WJ. Morphologic changes following in vitro $\mathrm{CO}_{2}$ laser treatment of calculus-ladened root surfaces. Lasers Surg Med 1996; 18:150-156

52. González M, Banderas JA, Rodríguez V, Castaño VM. Particle-induced X-ray emission and scanning electron microscopic analyses of the effects of $\mathrm{CO}_{2}$ laser irradiation on dentinal structure. J Dent 1999;27:595-600.

53. Sasaki KM, Aoki A, Masuno H, Ichinose S, Yamada S, Ishikawa I. Compositional analysis of root cementum and dentin after Er:YAG laser irradiation compared with $\mathrm{CO}_{2}$ lased and intact roots using Fourier transformed infrared spectroscopy. JPeriodontal Res 2002;37:50-59.

54. Lan WH, Chen KW, Jeng JH, Lin CP, Lin SK. A comparison of the morphological changes after Nd: YAG and $\mathrm{CO}_{2}$ laser irradiation of dentin surfaces. $J$ Endod 2000;26:450-453.

55. Read RP, Baumgartner JC, Clark SM. Effects of a carbon dioxide laser on human root dentin. JEndod 1995; 21:4-8.

56. Qadri T, Miranda L, Tunér J, Gustafsson A. The shortterm effects of low-level lasers as adjunct therapy in the treatment of periodontal inflammation. J Clin Periodontol 2005;32:714-719.

57. Kreisler $M$, Meyer C, Stender E, Daubländer $M$, Willershausen-Zönnchen B, d'Hoedt B. Effect of diode aser irradiation on the attachment rate of periodontal 
ligament cells: An in vitro study. J Periodontol 2001;72: 1312-1317.

58. Kreisler M, Daubländer M, Willershausen-Zönnchen B, d'Hoedt B. Effect of diode laser irradiation on the survival rate of gingival fibroblast cell cultures. Lasers Surg Med 2001;28:445-450.

59. Kreisler M, Christoffers AB, Willershausen B, d'Hoedt B. Effect of low-level GaAlAs laser irradiation on the proliferation rate of human periodontal ligament fibroblasts: An in vitro study. J Clin Periodontol 2003;30: 353-358.

60. Ozawa Y, Shimizu N, Abiko Y. Low-energy diode laser irradiation reduced plasminogen activator activity in human periodontal ligament cells. Lasers Surg Med 1997;21:456-463.

61. Heijl L. Periodontal regeneration with enamel matrix derivative in one human experimental defect. A case report. J Clin Periodontol 1997;24:693-696.

62. Sculean A, Schwarz F, Chiantella GC, Arweiler NB, Becker J. Nine-year results following treatment of intrabony periodontal defects with an enamel matrix derivative: Report of 26 cases. Int J Periodontics Restorative Dent 2007;27:221-229.

63. Sculean A, Schwarz F, Miliauskaite A, et al. Treatment of intrabony defects with an enamel matrix protein derivative or bioabsorbable membrane: An 8-year follow-up split-mouth study. J Periodontol 2006;77: 1879-1886.

64. Silvestri M, Rasperini G, Euwe E. Enamel matrix derivative in treatment of infrabony defects. Pract Periodontics Aesthet Dent 1999;11:615-616, 618.

65. Mariotti A. Efficacy of chemical root surface modifiers in the treatment of periodontal disease. A systematic review. Ann Periodontol 2003;8:205-226.

66. Caffesse RG, Holden MJ, Kon S, Nasjleti CE. The effect of citric acid and fibronectin application on healing following surgical treatment of naturally occurring peri- odontal disease in beagle dogs. $J$ Clin Periodontol 1985; 12:578-590.

67. Lowenguth RA, Blieden TM. Periodontal regeneration: Root surface demineralization. Periodontol 2000 1993; 1:54-68.

68. Misra V, Mehrotra KK, Dixit J, Maitra SC. Effect of a carbon dioxide laser on periodontally involved root surfaces. J Periodontol 1999;70:1046-1052.

69. Schwarz F, Sculean A, Berakdar M, Szathmari L, Georg $\mathrm{T}$, Becker J. In vivo and in vitro effects of an Er:YAG laser, a GaAlAs diode laser, and scaling and root planing on periodontally diseased root surfaces: A comparative histologic study. Lasers Surg Med 2003; 32:359-366.

70. Trylovich DJ, Cobb CM, Pippin DJ, Spencer P, Killoy WJ. The effects of the Nd:YAG laser on in vitro fibroblast attachment to endotoxin-treated root surfaces. J Periodontol 1992;63:626-632.

71. Steffensen B, Webert HP. Relationship between the radiographic periodontal defect angle and healing after treatment. J Periodontol 1989;60:248-254.

72. Cortellini P, Tonetti MS. Focus on intrabony defects: Guided tissue regeneration. Periodontol 2000 2000;22: 104-132.

73. Mangot D. The LANAP protocol: The legend continues. Dent Today 2013;32:130, 132.

74. Cobb CM. Lasers in periodontics: Use and abuse. Compend Contin Educ Dent 1997;18: 847-852, 854845, 858-849; quiz 860.

Correspondence: Dr. Hom-Lay Wang, Department of Periodontics and Oral Medicine, School of Dentistry, University of Michigan, 1011 North University Ave., Ann Arbor, MI 481091078. Fax: 734/936-0374; e-mail: homlay@umich.edu.

Submitted April 2, 2015; accepted for publication July 23, 2015. 